\title{
Uso das rúbricas de avaliación, a avaliación entre pares e a auto- avaliación para mellorar as competencias do alumno
}

\author{
Naves García-Rendueles, Acacia
}

E.T.S. Enxeñaría de Camiños, Canais e Portos, Universidade da Coruña.

\section{RESUMO (ABSTRACT)}

Na materia Sistemas de Abastecemento e Saneamento do Mestrado Internacional de Enxeñaría da Auga trabállanse as competencias transversais comunicativas, de consulta e selección de información e de avaliación crítica. Os alumnos realizan tarefas que consisten na revisión de referencias, a selección e organización de información e a presentación oral ou nun póster dun tema incluído nos contidos materia. Durante a presentación oral na clase, os alumnos dispoñerán dunha rúbrica na que deberán avaliar as presentacións dos seus compañeiros (avaliación entre pares) e despois a súa. Por último, a profesora avalía tamén a presentación. A nota final calcúlase a partir dos tres tipos de avaliacións e penalizarase aos estudantes que non realicen as avaliacións con rigor. Nestas actividades é fundamental que os criterios de avaliación sexan adecuados e que os alumnos os coñezan dende 0 inicio da actividade para dirixir 0 seu traballo. A avaliación entre pares fomenta que 0 alumno faga un esforzo para transmitir o mensaxe aos seus compañeiros. Por outra banda, obrígase indirectamente a prestar atención ao traballo dos compañeiros e, por tanto, apréndese dos contidos da materia. Na autoavaliación 0 alumno xulga os seu aprendizaxe e as súas fortalezas e debilidades na comunicación.

PALABRAS CLAVE: criterios de avaliación, auto-avaliación, avaliación entre pares, rúbrica 


\section{CITA RECOMENDADA:}

Naves García-Rendueles, J.(2019): Uso das rúbricas de avaliación, a avaliación entre pares e a autoavaliación para mellorar as competencias do alumno En De la Torre Fernández, E. (ed.) (2019). Contextos universitarios transformadores: construíndo espazos de aprendizaxe. III Xornadas de Innovación Docente. Cufie. Universidade da Coruña. A Coruña (pág. 291-300).

DOl capítulo: https://doi.org/10.17979/spudc.9788497497121.291

DOI libro: https://doi.org/10.17979/spudc.9788497497121

\section{ABSTRACT}

The transversal competences of communication, review and selection of references and critical assessment are practiced in the subject Systems of Supply and Sanitation of the International Master's in Water Engineering. Students carry out tasks that consist on the review of references, the selection and management of information and the oral or poster presentation about some of the subject contents. During the oral presentations, the students account for a rubric in which they have to evaluate the work of their peers (peer review) and their own work. Finally, the teacher also evaluates the presentation. The final mark is calculated from the three types of assessment and students who do not perform a rigorous assessment will be penalized. Appropriated assessment criteria that the students know from the beginning of the activity are required. Peer evaluation encourages students to make an effort to convey the message to their peers. On the other hand, they are indirectly obliged to pay attention to the presentations of their colleagues and, therefore, learn about contents of the subject. In the selfassessment the student judges their learning and their strengths and weaknesses in communication.

KEY WORDS: $\quad$ assessment criteria, self-assessment, peer review assesmet, rubric 


\section{INTRODUCCIÓN}

A materia Sistemas de Abastecemento e Saneamento impártese no Mestrado Internacional de Enxeñaría da Auga da Universidade da Coruña (UDC). 0 Mestrado é un título conxunto da UDC e da Hochschule Magdeburg-Stendal (Magdeburg, Alemania) que se cursa entre a Escola Técnica Superior de Camiños, Canais e Portos e a escola técnica alemá.

Unha das peculiaridades deste mestrado é que os estudantes presentan perfís moi diferentes polos diferentes estudos previos, xa que se trata dun mestrado multidisciplinar, e polos seus diferentes orixes. Algúns estudantes teñen un grao de enxeñería civil e xa deseñaran sistemas de abastecemento e drenaxe e, pola contra, outros veñen dun grado de enxeñería ambiental ou química e non teñen ningún coñecemento básico de hidráulica. As múltiples nacionalidades tamén xeran diferencias culturais. Como exemplo, no curso 2018-2019 están a cursar 0 mestrado 16 alumnos entre os que se atopan 8 nacionalidades diferentes. Os diferentes perfís dos alumnos supoñen un reto porque é preciso deseñar actividades que todos sexan capaces de resolver e que supoña unha aprendizaxe para cada un. Pola outra banda a multidisciplinariedade ten vantaxes. Integrar os diferentes puntos de vista para abordar un problema e complementar os coñecementos de uns cos dos outros supón unha aprendizaxe para o futuro profesional.

Outra das características do mestrado é que se imparte en inglés. Os profesores non somos nativos e a maior parte dos alumnos tampouco. Este feito complica manter a atención e comprender a materia aos alumnos e alumnas. É preciso, polo tanto, facer un esforzo para que os alumnos se impliquen na clase e traballen a materia. A vantaxe neste caso é que o feito de comprender, traballar e comunicarse en inglés supón por si mesmo unha destreza moi valorada no mercado laboral.

As peculiaridades deste mestrado teñen dúas consecuencias moi claras: (1) A introdución de metodoloxías activas na clase non é só unha boa práctica pola que opta o profesor, senón unha ferramenta imprescindible, e (2) As competencias comunicativas son competencias clave do aprendizaxe moi valoradas polos estudantes desta titulación. 
Entre as competencias transversais da materia Sistemas de Abastecemento e Saneamento pódense encontrar competencias de consulta e selección de información, comunicativas e de avaliación crítica. É por iso que os alumnos realizan tarefas que consisten na revisión de referencias, a selección e organización de información e presentación dun tema incluído na materia. Neste traballo preséntase a experiencia no deseño da metodoloxía seguida e a súa avaliación e como a avaliación é utilizada como ferramenta de aprendizaxe.

\section{DESCRICIÓN DA EXPERIENCIA}

Realízanse dúas actividades na materia nas que 0 alumnado traballa revisión de referencias, a selección e organización de información e presentación dun tema. Na primeira delas, a presentación é oral e, na segunda, está apoiada nun póster.

Estas actividades comezaron no curso 2015-2016, no que só se realizou a primeira delas. Escolleuse 0 tema "As válvulas nas redes de abastecemento". Asignouse a cada estudante un tipo de válvula e indicóuselle que tiña que facer unha presentación do tipo de válvula asignado explicando como era, como funcionaba e para que servía. Só se deron instrucións concretas do tempo dispoñible para a presentación, que era de entre 5 e 10 minutos. Os estudantes buscaron información por internet. As presentación fixéronse na clase diante dos compañeiros e a profesora avaliou o traballo de cada alumno.

Detectáronse varios problemas nos traballos e as presentacións. 0 primeiro é os alumnos buscaban no Google e copiaban o primeiro que atopaban. Nuns casos acertaban, mais en outros falaban de válvulas que nada tiñan que ver cos sistemas de abastecemento. Encontráronse tamén traballos de moi diferentes niveis. 0 feito de que a profundidade coa que tratar o tema non fose establecida previamente de ningunha maneira complicou a avaliación. En xeral os alumnos estaban bastante perdidos do que tiñan que facer e do que se esperaba deles.

No curso 2016-2017, repetiuse a actividade pero neste caso déronse instrucións concretas tanto sobre 0 contido como das características da presentación. Entregouse por escrito 0 
enunciado do exercicio onde viñan listados os contidos mínimos da presentación: tipo de bomba, funcionamento, esquema, vantaxes do seu uso e foto dun exemplo real. Estableceuse ademais dunha duración da presentación, o número máximo de diapositivas da presentación. Xusto antes das presentacións se entregou aos alumnos unha rúbrica na que tiñan que avaliar o contido e a calidade da presentación dos seus compañeiros. A avaliación dos compañeiros supoñía $020 \%$ da nota e a da profesora 0 80\%. Esta actividade de avaliación entre pares non foi avisada previamente. Neste curso, as presentacións respondían ao esperado pola profesora en canto a contidos. Os alumnos responderon mellor cando estaba máis claro 0 que se esperaba deles. As presentacións axustáronse mellor aos tempos estimados pero non se percibiron melloras nas competencias comunicativas dos alumnos. 0 feito de avaliar aos compañeiros incrementou lixeiramente a atención ás presentacións. Pola outra banda, os estudantes parecían un pouco perdidos e incómodos por avaliar aos compañeiros. A avaliación non pareceu moi rigorosa.

No curso seguinte, 2017-2018, tomáronse novas medidas. No enunciado da actividade incluíronse os contidos mínimos pero dun xeito diferente: como unha lista de aspectos que se van avaliar da presentación. Como exemplo, úsase "Ten que quedar claro como funciona a válvula" en lugar de "Funcionamento da válvula". Engadíronse aos contidos mínimos os requirimentos de formato da presentación que van ser tamén avaliados. Os alumnos foron informados no enunciado de que eses aspectos eran os que ían ser avaliados. Informouse tamén aos alumnos de que se ía facer unha avaliación entre pares seguindo unha rúbrica cos aspectos indicados e que cada un ía a avaliar tamén o seu propio traballo. Comunicouse que a avaliación da profesora valería $050 \%$ da nota e a avaliación da clase, incluíndo a propia, valería 0 outro 50\%. Como resultado, as presentacións continuaron a responder ao esperado pola profesora en canto a contidos e as presentacións melloraron considerablemente. 0 feito de ter claros os criterios de avaliación e saber que os compañeiros ían xulgar se as presentacións deixaban claros os contidos trouxo un maior esforzo en mellorar a comunicación coa clase. Por outra banda, unha rúbrica máis detallada fixo que os alumnos se 
sentiran menos incómodos. Non se trataba neste caso de pór unha nota ao compañeiro, senón de contestar se a presentación cumpría ou non certas condicións nunha rúbrica da que foran avisados. A atención da clase ás presentacións foi moito maior e observouse un claro esforzo de mellora da capacidades comunicativas. Ademais, o feito de saber que a súa avaliación tiña moita relevancia na cualificación que levaría o alumno, fixo que os alumnos realizaran a avaliación entre pares con máis rigor.

No curso 2016-2017, traballouse nunha actividade nesta mesma liña que consistiu na revisión de referencias, a selección e organización de información e a presentación dunha parte dun tema apoiándose nun póster. Esta actividade está incluída no bloque de Sistemas de drenaxe urbano sustentable (SUDS) da materia. Na primeira parte do bloque, a profesora fixo unha introdución aos SUDS explicando que son e describindo os diferentes tipos. Despois presentouse a actividade que consistiu na elección dunha técnica SUDS e a preparación dun póster que foi exposto e defendido durante unha clase. Tendo en conta a experiencia previa coas presentacións orais, entregouse un enunciado por escrito onde se deixaban claros os contidos que debían ser incluídos no traballo. A elección dos pósters foi feita pola profesora e os pósters foron, unicamente, avaliados pola profesora.

No curso 2017-2018 repetiuse a actividade incorporando melloras. No primeiro lugar, a elección dos SUDS foi feita polos alumnos por orde de inscrición nun foro aberto en Moodle con esa finalidade. No enunciado da actividade incluíronse os aspectos dos contidos e do formato do póster que se van a avaliar, coa intención de dirixir o traballo dos alumnos. Tamén se informou de que cada alumno ía a avaliar os traballos dos compañeiros e o seu propio utilizando unha rúbrica cos criterios coñecidos. A media desas calificacións suporía $050 \%$ da nota. 0 outro $50 \%$ correspondería a avaliación da profesora. Tras pasar a data límite de entrega, os pósters foron impresos e expostos nas paredes do aula como se se tratara dun congreso. Nunha das clases, repartíronse rúbricas para realizar a avaliación entre pares e a auto-avaliación. Cada autor defendeu o seu traballo brevemente e todos recorreron os pósters 
lendo e facendo a avaliación. A Figura 1 mostra o momento no que os alumnos están a avaliar os pósters dos compañeiros expostos no aula.

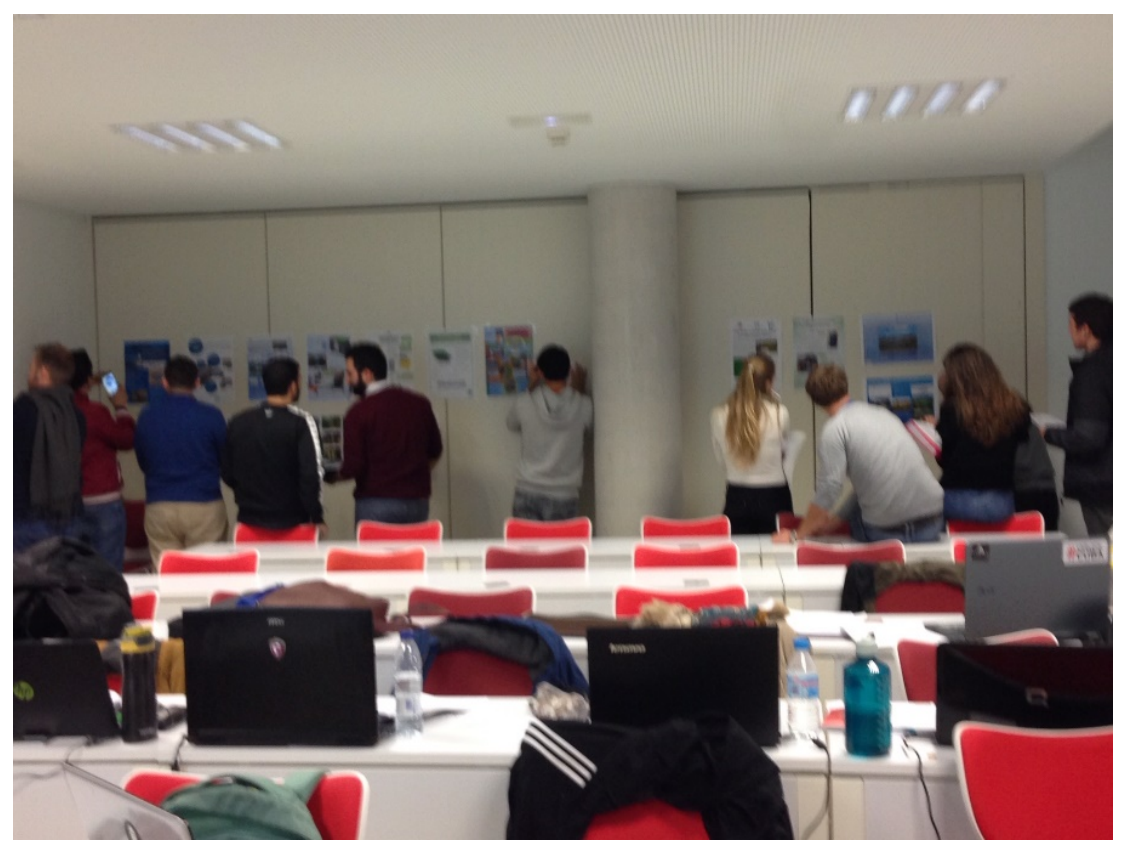

Figura 1. Alumnos e alumnas do mestrado durante a exposición e avaliación dos pósters.

Coma no caso das presentacións orais, os contidos dos pósters e o formato foron adecuados. Coñecer os criterios de avaliación e saber que os compañeiros van avaliar o seu traballo incrementa 0 esforzo na comunicación. A rúbrica facilitou a avaliación e a porcentaxe da nota correspondente á avaliación dos alumnos fixo que se tomaran en serio esta parte da actividade.

\section{RESULTADOS E CONCLUSIÓNS}

No camiño seguido do uso de metodoloxías activas na materia Sistemas de abastecemento e saneamento incluíronse dúas actividades que consisten na busca e revisión de información dun tema, a súa análise e a presentación dun resumo do tema. A primeira delas trátase dunha 
presentación oral de entre 5 e 10 minutos apoiada en diapositivas. A outra consistiu na elaboración e breve defensa dun póster. Ambas actividades permiten abordar parte dos contidos da materia á vez que se traballan as competencias comunicativas en inglés.

A avaliación das actividades fíxose mediante rúbricas e os criterios de avaliación estaban dispoñibles para 0 alumno dende 0 principio da actividade. Os traballos foron avaliados na clase polos compañeiros, por eles mesmos e posteriormente pola profesora. A avaliación foi utilizada polo como ferramenta de aprendizaxe, destacando os seguintes aspectos:

- 0 uso de rúbricas de avaliación, cuxos criterios se facilitan aos estudantes dende 0 inicio da actividade, orienta 0 traballo dos alumnos aos aspectos que o docente considera máis importantes. A selección de contidos e a súa análise mellora, ao ter claro cales son os conceptos fundamentais. Obsérvase unha mellora das competencias comunicativas dos estudantes ao focalizar a atención aos aspectos clave dunha presentación de calidade. Polo tanto, o coñecemento dos criterios de avaliación orienta o traballo do alumno aos conceptos máis relevantes e á mellora das súas destrezas.

- Complementar a avaliación da profesora coa avaliación entre pares aumenta 0 esforzo dos alumnos por transmitir a mensaxe aos compañeiros e por facer unha boa presentación de boa calidade. Isto se debe a que a comprensión dos contidos polos compañeiros e a boa imaxe do traballo suporán a metade da nota da actividade.

- A avaliación entre pares tamén obriga indirectamente a todos os estudantes a prestar atención ao traballo dos compañeiros. Aprenderán, polo tanto, dos contidos das outras presentacións e dos acertos e os erros na comunicación dos compañeiros. Tamén fomenta a capacidade de análise crítica, que é unha competencia transversal da materia.

- A auto-avaliación obriga ao alumno a xulgar a súa aprendizaxe e as súas fortalezas e debilidades na comunicación. 
Outras leccións aprendidas desta experiencia son as seguintes:

- Dedicar tempo á presentación dos traballos na clase é fundamental para transmitir aos alumnos a importancia das competencias comunicativas e para a súa mellora.

- Os enunciados das actividades hai que entregalos sempre escritos e deben conter os criterios de avaliación concretos. Estes criterios non deben ser xerais como por exemplo "Contido", senón que deben ser cuestións máis específica as que poda darse unha resposta clara como por exemplo "Conten unha definición clara do concepto". Trátase de que os estudantes teñan claro que é o que se espera deles. Este tipo de rúbrica denomínase rúbrica activa.

- É preciso facilitar aos alumnos a avaliación dos traballos dos seus compañeiros mediante 0 uso de rúbricas detalladas. Pódese dar o caso de que unha avaliación moi aberta faga sentir incómodo ao estudante, posto que a nota dependerá dos aspectos aos que lle dea maior importancia. Deste xeito, a avaliación tórnase máis subxectiva e pode afectar á relación persoal. Todo isto se reduce na medida en que se definan uns criterios de avaliación claros e coñecidos por avaliador e avaliado.

- 0 uso de rúbricas detalladas tamén aumenta a atención dos alumnos durante as presentacións dos compañeiros, posto que precisa coñecer detalles de cada presentación.

- É preciso darlle un peso importante á avaliación entre pares na nota final para que os alumnos o perciban como unha parte seria da actividade e a afronten con rigor. Nalgún caso poderíase impoñer penalización na nota final se esta tarefa non se fai con seriedade.

As conclusións respecto ao uso de rúbricas e ao uso da avaliación como ferramenta de aprendizaxe están de acordo polas apuntadas anteriormente por outros autores como Fernandez March, A. (2010), Carrizosa \& Gallarfo (2011) 0 Andrade \& Andrade (2017). 


\section{REFERENCIAS}

Andrade, L. \& Andrade, M. (2017). Uso de las rúbricas en ambientes virtuales de aprendizaje. $\begin{array}{lll}\text { Revista Educación y 102-110, } & \text { 19(32), Humanismo, }\end{array}$ http://dx.doi.org/10.17081/eduhum.19.32.2535

Carrizosa, E. \& Gallardo, J. I. (2011). Rúbricas para la orientación y evaluación del aprendizaje en entornos virtuales. En: II Jornadas sobre docencia del derecho y tecnologías de la información y la comunicación, UOC. Disponible on line en: http://www.uoc.edu/symposia/dret_tic2011/pdf/4.carrizosa_prieto_esther_gallardo_ballestero jose.pdf

Fernandez March, A. (2010). La evaluación orientada al aprendizaje en un modelo de formación por competencias en la educación universitaria. REDU, 8(1). 